\title{
Teoria da Aprendizagem Experiencial de Kolb e o Ciclo de Belhot Guiando o Uso de Simulações Computacionais no Processo Ensino Aprendizagem
}

\author{
Maria das Graças Bruno Marietto, Wagner Tanaka Botelho, \\ João Carlos da Motta Ferreira, Edson Pinheiro Pimentel \\ Universidade Federal do ABC (UFABC) \\ Centro de Matemática, Computação e Cognição - Santo André, SP, Brasil \\ \{graca.marietto, wagner.tanaka, joao.cmferreira,edson.pimentel \} \\ eufabc.edu.br
}

\begin{abstract}
The main target of this work is to rethink the idea to use the computer simulations in higher education. In order to structure a set of computational simulation in laboratories, a pedagogical proposal is presented with the Kolb's Experiential Learning Theory and the Belhot's Learning Cycle. The chosen content to be study is the Ant Colony Optimization Technique that is adapted and implemented in the RoboMind software.
\end{abstract}

Resumo. O objetivo principal deste trabalho é contribuir no repensar do uso de simulações computacionais no ensino superior. Uma proposta pedagógica é apresentada com a aplicação da Teoria da Aprendizagem Experiencial de Kolb e do ciclo de aprendizagem de Belhot para estruturar um conjunto de atividades de simulação computacional em laboratórios. O conteúdo escolhido para ser ensinado é a técnica Ant Colony Optimization, tendo sido adaptada e implementada no software RoboMind.

\section{Introdução}

Simulações computacionais são utilizadas para estudar um sistema por meio de experimentos, atuando como um laboratório no qual teorias e hipóteses podem ser desenvolvidas e exploradas. Apesar da simulação computacional estar sendo cada vez mais utilizada no contexto educacional, geralmente ela tem sido aplicada dentro de uma proposta tradicional de acúmulo de contéudo e reprodução do conhecimento. Assim, faz-se necessário um repensar do papel de atividades práticas de laboratório, especificamente o uso de simulações computacionais como uma ferramenta didática de suporte ao processo de ensino-aprendizagem.

Objetivando contribuir neste repensar do uso do ferramental teórico-técnico da simulação computacional no processo educacional, neste trabalho uma proposta pedagógica é estruturada para investigar a aplicação da Teoria de Aprendizagem Experiencial de Kolb [Kolb 1976, Kolb 1984] e o ciclo de apredizagem de Belhot (1997) na elaboração de aulas que utilizem simulações computacionais como recurso instrucional. A proposta pedagógica deste trabalho está desenvolvida para ser aplicada em cursos de graduação que tenham atividades que alternem adequadamente ações de foco teórico com atividades práticas, utilizando o computador no processo educacional. Como exemplo de uma disciplina com estas características pode-se citar Bases 
Computacionais da Ciência da Universidade Federal do ABC (UFABC), oferecida para o primeiro ano de treze cursos de bacharelado, cinco cursos de licenciatura e oito cursos de graduação em Engenharia. Esta disciplina objetiva apresentar conceitos de Computação e suas relações nas diversas áreas do conhecimento. Nesta disciplina softwares são utilizados para o apoio no processo de ensino aprendizagem. Dentre estes softwares cita-se o RoboMind [Halma 2014], um software educacional para ensino de lógica e linguagem de programação, por meio da construção de programas que visam o controle das ações de um robô.

A proposta pedagógica deste artigo tem por objetivo elaborar um plano de aulas para o ensino do conceito de otimização, mais especificamente a técnica Ant Colony Optimization (ACO) [Dorigo et al. 1999]. A escolha da técnica ACO deveu-se ao fato de ser uma heurística de propósito geral e com uma modelagem intuitiva que permite ser apresentada aos alunos desde o primeiro ano do ensino superior. Esta proposta também pode servir como guia de referência para a estruturação de planos de ensino de uma variedade de conteúdos, que usem simulações computacionais como ferramenta didática.

\section{Teoria de Aprendizagem Experiencial de Kolb e Ciclo de Aprendizagem de Belhot no Processo Ensino Aprendizagem}

A teoria da aprendizagem experiencial de Kolb é um modelo de representação de como as pessoas aprendem, e este modelo atribui grande valor ao papel da experiência na aprendizagem. Kolb descreve o processo de aprendizagem tendo como base um ciclo contínuo de quatro estágios, quais sejam (veja Tabela 1): Experiência Concreta, Observação Reflexiva, Conceitualização Abstrata e Experimentação Ativa.

Tabela 1: Estágios do Ciclo de Aprendizagem Experiencial de Kolb.

\begin{tabular}{c|l}
\hline ESTÁGIO & \multicolumn{1}{c}{ DESCRIÇÃO } \\
\hline $\begin{array}{c}\text { Experiência } \\
\text { Concreta }\end{array}$ & $\begin{array}{l}\text { Os estudantes têm experiências relacionadas a fazer uma tarefa. Eles trabalham com } \\
\text { uma nova experiência concreta, tendendo a tratar as situações mais em termos de } \\
\text { observações e sentimentos do que com uma abordagem teórica e sistemática. }\end{array}$ \\
\hline $\begin{array}{c}\text { Observação } \\
\text { Reflexiva }\end{array}$ & $\begin{array}{l}\text { Os estudantes estão envolvidos em observar, revendo e refletindo sobre a experiência } \\
\text { concreta do estágio anterior. As reflexões e observações neste estágio não incluem } \\
\text { necessariamente realizar alguma ação. }\end{array}$ \\
\hline $\begin{array}{c}\text { Conceitualização } \\
\text { Abstrata }\end{array}$ & $\begin{array}{l}\text { Neste estágio os estudantes se desenvolvem e agem no domínio cognitivo da situação } \\
\text { usando teorias, hipóteses e raciocínio lógico para modelar e explicar os eventos. }\end{array}$ \\
\hline Experimentação & $\begin{array}{l}\text { Os estudantes estão envolvidos em atividades de planejamento, experimentando } \\
\text { experiências que envolvem mudança de situações. Os estudantes usam as teorias para } \\
\text { tomar decisões e resolver problemas. }\end{array}$ \\
\hline
\end{tabular}

Kolb também identifica quatro estilos de aprendizagem, quais sejam: divergente, assimilador, convergente e acomodador. Os estilos de aprendizagem são preferências na forma de perceber, organizar, processar e compreender a informação. Para Kolb a aprendizagem eficaz requer o movimento cíclico passando pelos quatro estilos de aprendizagem, embora usualmente estudantes prefiram um estilo em detrimento dos outros. Por este motivo Kolb postulou que os estudantes desenvolvem-se mais em um destes estilos. Os estilos de aprendizagem de Kolb, apresentados em Kolb (1976) e Kolb (1984) são descritos na Tabela 2. 
Tabela 2: Estilos de Aprendizagem de Kolb.

\begin{tabular}{c|l}
\hline ESTILO & \multicolumn{1}{c}{ CARACTERÍSTICAS DOS ALUNOS } \\
\hline Divergente & $\begin{array}{l}\text { Têm como pontos fortes a criatividade e a imaginação. Recebem este nome por serem } \\
\text { bons em situações que necessitem gerar uma variedade de ideias e implicações } \\
\text { alternativas. A pergunta característica desse tipo de estudante é "Por quê?". }\end{array}$ \\
\hline Assimiladores & $\begin{array}{l}\text { São fortes na criação de modelos teóricos e raciocínio indutivo, não focando no uso } \\
\text { prático de teorias. Suas perguntas características são "O que há para se conhecer?" e } \\
\text { "O que isto significa?". }\end{array}$ \\
\hline Convergente & $\begin{array}{l}\text { Destacam-se na resolução de problemas, tomada de decisões e aplicação prática de } \\
\text { ideias. Utilizam raciocínio dedutivo e recebem este nome porque trabalham melhor } \\
\text { em situações em que há uma só solução a uma pergunta ou problema. As perguntas } \\
\text { características desse tipo de estudante são "Como?" e "O que eu posso fazer?". }\end{array}$ \\
\hline Acomodadores & $\begin{array}{l}\text { Gostam de experiências práticas ao invés de uma abordagem teórica. Eles geralmente } \\
\text { assumem riscos e resolvem problemas de uma maneira intutiva e em uma abordagem } \\
\text { de tentativa e erro. As perguntas características desse tipo de estudante são "O que } \\
\text { aconteceria se eu fizesse isto?" e "Por quê não?". }\end{array}$ \\
\hline
\end{tabular}

Belhot (1997) propõe um ciclo de aprendizagem com estágios pelos quais um aluno deve passar para a construção do conhecimento. No estágio "Por quê" os alunos precisam entender os motivos que levam ao estudo de determinado tema. Para tanto, o tema deve ser apresentado e discutido com os estudantes, abordando itens tais como: relevância, seu relacionamento com situações reais, problemas encontrados e possíveis soluções. Na etapa "O que" o professor deve escolher um problema relacionado ao conteúdo e apresentar os conhecimentos necessários para a construção de sua resolução.

No estágio "Como" os conceitos e ferramental teórico apresentados na etapa anterior devem ser aplicados na solução do problema selecionado pelo professor. Esta é uma fase de sedimentação do conhecimento adquirido e tem como objetivo a integração da teoria com a prática com problemas bem-estruturados. No estágio "Se" o aluno deve transpor o que aprendeu para novas situações que envolvam variação de parâmetros ou outras condições de contorno de um problema.

\section{Uma Proposta Pedagógica usando a Simulação Computacional como Ferramenta Didática}

A proposta pedagógica deste trabalho organiza atividades práticas a serem desenvolvidas em laboratórios, tendo como base o uso de simulações computacionais para o ensino da técnica ACO. Esta proposta é formada por quatro sessões, com duas horas de duração cada uma. Para que os alunos não fiquem presos em apenas um estágio e estilo de aprendizagem, as atividades de cada sessão devem ser estruturadas para que os alunos sejam expostos aos quatro estágios de Kolb e Belhot.

\subsection{As Sessões}

Na Subseção 3.1.1 as atividades são apresentadas com mais detalhes, objetivando apresentar um exemplo de como as atividades devem ser estruturadas. Para as demais sessões são apresentados os objetivos educacionais que deverão nortear o planejamento das atividades.

\subsubsection{Primeira Sessão: Porque Estudar a Técnica ACO?}

Nesta sessão tem-se o início do ciclo de aprendizagem, tendo como principais objetivos educacionais: (i) apresentar os princípios da técnica ACO para os estudantes, 
contextualizando como uma técnica de otimização; (ii) justificar a importância deste estudo; (iii) despertar interesse no aluno por este tema; (iv) expor os alunos a diferentes abordagens do uso da técnica ACO; (v) desenvolver nos alunos as habilidades de criatividade e imaginação.

\section{Atividades em Sala de Aula}

Atividade 1 - Experiência Concreta de Kolb e Estágio Por Quê de Belhot: O professor apresenta conceitos sobre "Introdução à Otimização", abordando o tema a ser desenvolvido considerando itens tais como: definição de otimização, apresentação da ACO como uma técnica de otimização, princípios teóricos gerais da técnica ACO de Dorigo. Após esta apresentação os alunos devem procurar por vídeos na Internet que apresentem experimentos que utilizem a técnica ACO para encontrar um caminho ótimo, em uma área aberta ou em áreas específicas como um labirinto. Nos vídeos os estudantes devem identificar elementos tais como: formação do comportamento coletivo das formigas e uso do feromônio para marcar os caminhos. Esta atividade oferece aos alunos a oportunidade de experimentar uma experiência concreta, considerando a possibilidade de analisarem o funcionamento de um sistema em termos de "fazer", sentimentos e reações ao invés de uma abordagem teórica e sistêmica.

Atividade 2 - Observação Reflexiva de Kolb e Estágio O Que de Belhot: Os estudantes em grupos de 2 ou 3 devem discutir e comparar os vídeos encontrados na atividade anterior, tendo como base questões tais como: Como ocorre o processo de acúmulo de feromônio nos experimentos? Nesta atividade os estudantes devem refletir e reanalisar os vídeos anteriormente escolhidos sob uma nova perspectiva. O aprendizado neste momento depende de observações cuidadosas dos estudantes, para a posterior formação de opiniões e definição de julgamentos.

Atividade 3 - Conceitualização Abstrata de Kolb e Estágio Como de Belhot: Nesta atividade o professor irá reforçar os conceitos teóricos de otimização e a técnica ACO, tendo como base as experiências concretas, as observações e reflexões feitas pelos alunos nas atividades anteriores. Aqui os estudantes estão envolvidos em pensar e na formação de uma teoria, hipóteses ou princípios a partir do que foi experienciado.

Atividade 4 - Experimentação Ativa de Kolb e Estágio Se de Belhot: Esta atividade deve ser feita como tarefa para casa. Os alunos são direcionados a procurar por um trabalho que aplique a técnica em uma área de seu interesse. Além disto, devem apresentar na próxima sessão um poster para ilustrar as principais ideias do trabalho selecionado. Esta atividade semi-estruturada desafiará o aluno a transpor o que aprendeu para um novo contexto, tendo que assumir o "risco" de escolher um artigo mais adequado aos seus conhecimentos e preferências.

\subsubsection{Segunda Sessão: Importância do Embasamento Teórico}

Nesta sessão os estudantes são apresentados à técnica ACO, de maneira mais detalhada. Os principais objetivos são: (i) apresentar o problema a ser resolvido: modelar e implementar no RoboMind o experimento da ponte binária de Dorigo; (ii) apresentar de maneira clara a base teórica da técnica ACO, com conceitos que serão utilizados pelos alunos para a resolução do problema proposto; (iii) refletir sobre o que foi feito na 
experiência concreta da primeira sessão, levando em consideração o base teórica apresentada nesta aula; (iv) desenvolver nos alunos um raciconío lógico e estruturado.

\subsubsection{Terceira Sessão: Integrando a Teoria com a Prática}

Nesta sessão os conceitos apresentados nas aulas anteriores são aplicados na resolução do problema considerado, qual seja: modelar e implementar a simulação do experimento da ponte binária de Dorigo no RoboMind. Os principais objetivos desta sessão são: (i) consolidar os conceitos teóricos da técnica ACO; (ii) integrar os conceitos da técnica ACO com a atividade prática de sua implementação no RoboMind, dentro do contexto do experimento da ponte binária; (iii) desenvolver nos alunos habilidades de resolução de problemas, tomada de decisão, criatividade e aplicação prática de ideias.

\subsubsection{Quarta Sessão: Planejando Novas Experiências}

Nesta sessão os alunos devem transpor o que aprenderam até o momento para novas situações que envolvam variação de parâmetros ou outras condições de contorno. Os principais objetivos educacionais desta aula são: (i) direcionar os alunos para usarem as teorias e técnicas aprendidas nas aulas anteriores para a resolução de novos problemas e na tomada de decisão; (ii) trabalhar com problemas semi-estruturados com ênfase na experimentação; (iii) encorajar para que o aprendizado ocorra de maneira independente, em um processo de descoberta; (iv) desenvolver nos alunos habilidades tais como criatividade e escolha de uma boa solução dentre várias soluções alternativas.

\section{Conclusões e Trabalhos Futuros}

A proposta pedagógica deste trabalho contribui no repensar do uso de simulações computacionais como ferramenta didática no ensino superior, sob a luz da Teoria da Aprendizagem Experiencial de Kolb e do ciclo de aprendizagem de Belhot. Como exemplo de pesquisas futuras, as implicações pedagógicas da proposta deste trabalho precisam ser investigadas em uma variedade de estudos de caso reais, visando avaliar empiricamente como professores e alunos são influenciados por esta forma experiencial e construtivista de processo educacional.

\section{Agradecimentos}

Os autores agradecem ao Conselho de Desenvolvimento Científico e Tecnológico (CNPq) pelo apoio financeiro, projeto $\mathrm{n}^{0} 560067 / 2010-0$.

\section{Referências Bibliográficas}

Belhot, R.V. Reflexões e propostas sobre o "ensinar engenharia para o século XXI". Tese (Livre Docência), EESC, Universidade de São Paulo, São Carlos, 1997.

Dorigo, M.; Caro, G.; Gambardella, L.M. Ant algorithm for discrete optimization, Artificial Life, v. 5, n. 2, pp. 137-172, 1999.

Halma, A. Welcome to Robomind.net. 2014. Acesso em 21 de Julho de 2014. Disponível em < http://www.robomind.net>.

Kolb, D.A. The learning style inventory, Boston, Ma.: McBer, Technical Manual, 1976.

Kolb, D. A. Experiential learning. Prentice-Hall, Englewood Cliffs, New Jersey, 1984. 